\title{
Short and Medium Term Results of Posterior Segmental Instrumentation and Posterolateral Fusion in Female Patients with Spondylolisthesis: A Clinical Trial
}

\author{
Spondilolistezli Kadın Hastalarda Posterior Segmental \\ Enstrümantasyon ve Posterolateral Füzyonun Kısa ve Orta Vadeli \\ Sonuçları: Klinik Çalışma
}

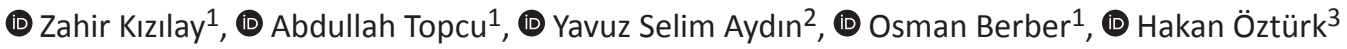

${ }^{1}$ Aydın Adnan Menderes University Faculty of Medicine, Department of Neurosurgery, Aydın, Turkey

${ }^{2}$ Uşak State Hospital, Clinic of Neurosurgery, Uşak, Turkey

${ }^{3}$ Aydın Adnan Menderes University Faculty of Medicine, Department of Biostatistics, Aydın, Turkey

\section{Keywords}

Spinal fusion, spinal surgery, pain, disability, spondylolisthesis

\section{Anahtar Kelimeler}

Omurga füzyonu, omurga cerrahisi, ağrı, sakatlık, spondilolistezis

Received/Geliş Tarihi : 22.12.2016 Accepted/Kabul Tarihi : 02.10.2017

\section{doi:10.4274/meandros.25744}

Address for Correspondence/Yazışma Adresi: Zahir Kızılay MD,

Aydın Adnan Menderes University Faculty of Medicine, Department of Neurosurgery, Aydın, Turkey

Phone : +90 5467385840

E-mail : zahir.kizilay@adu.edu.tr

ORCID ID: orcid.org/ 0000-0002-2021-0406

(C) Meandros Medical and Dental Journal, Published by Galenos Publishing House.

This is article distributed under the terms of the Creative Commons Attribution NonCommercial 4.0

International Licence (CC BY-NC 4.0).

\section{Abstract}

Objective: Aim of this study was to short and medium term results of posterior segmental instrumentation and posterolateral fusion in female patients with spondylolisthesis.

Materials and Methods: Patients with lumbar sponylolisthesis who were performed convetional laminectomy, poliaxial secrew fixation and posterolateral fusion between the 2013 and 2015. The postoperative fusions of the female patients were evaluated through lumbar 3D computed tomography and X-ray imaging. The patients' back pain and lower extremities's pain were evaluated with Oswestry Disability index and visual analogue score. Patients' information was collected retrospectively from their files in May 2016.

Result: When the pain scores of the patients who underwent segmental instrumentation were compared in the preoperative, postoperative periods there was the significant decrease in pain scores $(p<0.001)$.

Conclusion: The posterolateral fixation and fusion are an efficient treatment method in the medium and short term in female patients with spondylolisthesis. But, a secondary chronic disease such as osteoporosis associated with aging was added to impair bone quality, fusion success rate was seen to be decreased.

Öz

Amaç: Bu çalışmanın amacı, spondilolistezisli kadın hastalarda posterior segmental enstrümantasyon ve posterolateral füzyonun kısa ve orta vadeli sonuçlarının değerlendirmesidir.

Gereç ve Yöntemler: 2013-2015 yılları arası 50 spondilolistezisli kadın hastaya konvansiyonel laminektomi, poliaxial vida fiksasyon ve posterolateral füzyon yapıldı. Postoperatif dönemde hastaların füzyon durumları, 3D bilgisayarlı tomografi ve X-ray ile değerlendirildi. Hastaların bel ve alt ekstremite ağrıları sırayla Oswestry 
Disability indeksi and vizüel analog skoru ile değerlendirildi. Hastaların bilgileri, hastaların dosyaları aracılığı ile retrospektif olarak taranak Mayıs 2016'da elde edildi.

Bulgular: Hastaların preoperatif ve postoperatif ağrı skorları karşılaştırıldığında ağıı skorlarında önemli bir azalama vardı $(p<0,001)$. Sonuç: Posterolateral fiksasyon ve füzyon, spondilolistezisli kadın hastalarda kısa ve orta vadede etkili bir tedavi yöntemidir. Fakat yaşlanmayla ilişkili osteoporoz gibi ikincil hastalıkların eklenmesinin füzyon oranını azalttığı görüldü.

\section{Introduction}

Spondylolisthesis is defined as subluxation of the spine on another spine in the sagittal plane (1). The etiological causes of spondylolisthesis were classified as dysplastic, ischemic, degenerative, traumatic pathologic, and iatrogenic by Wiltse et al. Rothman (2). Besides the etiologic classification, spondylolisthesis was divided into 5 groups depending on degree of slip by Meyerding (3). While grade 1 and 2 were defined as low-grade spondylolisthesis, grade 3,4 and 5 were defined as high-grade spondylolisthesis (4). While the isthmic type whose etiological factors has not been fully revealed is often seen in young people, the degenerative type is often seen in the elderly group. It was reported that the incidence of spondylolisthesis in the lumbar region was $82 \%$ at L5-S1, $11 \%$ at L4$5,0.5 \%$ at $\mathrm{L} 3-4$ and $0.5 \%$ at L2-3, respectively (5). Spondylolisthesis often causes clinically lower back pain which is worsened with motion and the cause of lower back pain is a weakness in the bone bridge connecting the upper and lower facet joints each other or instability associated with motion due to fracture (6). The increased instability may accelerate the disc degeneration in the affected level over time and this situation may cause that non-symptomatic discs become symptomatic. Moreover, it causes impairment of sagittal balance in the spine depending on the degree of slip $(7,8)$.

The treatment options for spondylolisthesis include conservative treatment and surgical treatment. The conservative treatment is used frequently in patients with or without neurological deficit who have tolerable pain and improve with physical therapy. The surgical treatment is applied in patients with neurological deficit who do not benefit from physical therapy and conservative treatment (9). In the literature, many surgical techniques such as anterior interbody fusion, posterolateral fusion (PLF), posterior lumbar interbody fusion, circumflexial fusion, transforaminal interbody fusion and axial lumbar interbody fusion have been described (10-13). Although many different techniques have been described for the surgical treatment of spondylolisthesis, posterolateral lumbar fusion is regarded as the gold standard $(14,15)$.

In the literature, there are many studies related to posterolateral fixation and PLF for treating spondylolisthesis. In nearly all of these studies, male and female genders were evaluated together. However, female patients have a hormonal disadvantage such as the development of osteoporosis secondary to menopause occurred after depletion of ovarian reserve or surgical ovariectomy compared to male patients. Our retrospective study includes 50 female patients with spondylolisthesis. The preoperative visual analogue score (VAS), body mass index (BMI) and Oswestry Disability index (ODI) scores of the patients were obtained and then the postoperative fusion, VAS and ODI scores of the patients were compared. Finally, we discussed our results in the context of the literature.

\section{Materials and Methods}

\section{The Patients}

This retrospective study was conducted with patients' file information and the last patients' operations were performed in December 2015. This retrospective study's information was collected in May 2016. This study included fifty female patients with the mean age of $58.14 \pm 13.32$ (range: 34 to 79 years) who were operated by the same surgeon at Uşak State Hospital and Adnan Menderes University Medical Faculty Hospital between May 2013 and December 2015. The mean follow-up period was 22.06 \pm 9.12 months (range: 6 to 36 months). The grading of spondylolisthesis in the patients were made according to Meyerding classification. Twenty nine patients had grade 1 spondylolisthesis and 21 patients had grade 2 spondylolisthesis. Four patients had spondylolisthesis at L3-4 and above, 16 patients had spondylolisthesis at L4-5 and 17 patients had at L5-S1. Thirteen patients had spondylolisthesis at 2 or more levels. Twenty nine patients had single or multiple 
chronic disease. The chronic diseases of the patients were hypertension, Chronic Obstructive Pulmonary disease, hypothyroidism, primary biliary cirrhosis, chronic kidney failure, osteoporosis, osteopenia, type 2 diabetes, rheumatoid arthritis, epilepsy, and ovarian carcinoma. Four (8\%) patients had isolated radicular pain, $10(20 \%)$ patients had isolated lower back pain, $36(72 \%)$ patients had the combination of lumbar and leg pain. Fouteen (28\%) patients had motor and sensory deficits, $11(22 \%)$ patients had isolated sensory deficits, 25 (50\%) patients had no any motor or sensory deficit. Eight (16\%) had a 0-12 months follow-up period, 20 (40\%) patients had a 1324 months follow-up period, 22 (44\%) patients had a 25-36 months follow-up period.

\section{Surgical Technique}

Informed concsent forms were obtained from the all patients and their relatives before the surgical procedure. The detection of the spinal level was made using fluoroscopy after the patients were prepared in the prone position. Then iliolumbar muscles were bilaterally opened up to the transverse processes via the traditional posterior midline approach. During surgery, automatic retractor was used in order to rule out skin, subcutaneous and muscle tissue. After the spinal level was determined again with fluoroscopy, secondary stenosis and foraminal stenosis were treated using Kerrison Rong or ultrasonic bone shaver and then total laminectomy and bilateral foraminotomy were performed. The disc fragment was removed if any. The areas for fusion were formed by scraping the surfaces of the facet joints and the transverse processes using a drill after discectomy. Then posterolateral fixation was made using fluoroscopy and bilateral rods were placed. After fixation, the bones which were removed after laminectomy were converted to chip-shaped. Then they were mixed with rifamycin and were placed between the transverse processes previously formed for PLF. The layers were closed in accordance with the anatomy by placing a hemovac drain on distance.

\section{Intraoperative and Postoperative Complications}

After 1 patient had the inc reased radicular complaints during PLFand fixation, a lumbar 3D computed tomography (CT) was performed. The patient was operated again upon the determination of the screw malposition on lumbar CT. The dural tear occurred in two patients during laminectomy but they were treated with primary suture and bed rest. Her complaints were started again after lifted a load of 25 $\mathrm{kg}$ on the $1^{\text {st }}$ postoperative year. Then a lumbar CT was performed and the patient was operated again upon bilateral S1 rods were pull out on lumbar CT (Figure 1A-D). Unenhanced and contrast-enhanced lumbar magnetic rezonans imagining were performed upon 1 patient had fever on the $6^{\text {th }}$ postoperative day. The antibiotic treatment was started and was given i.v. for 14 days upon there was a contrast enhancement in the area of operation on lumbar CT. The root anomaly was seen in 2 patients in the intraoperative period. One patient had unilateral fracture of S1 screw after 1 year but we recommended follow-up because the patient had no any complaint.

\section{The Post-operative Medication of the Patients}

The infusion of tramadol was administered to the patients for the first 3 days in the postoperative period. Tramadol $50 \mathrm{mg} 2$ times per day and amoxicillinclavulanic acid 1000/125 mg 2 times per day were administered to the patients between the $3^{\text {rd }}$ and $10^{\text {th }}$ postoperative day. All patients were mobilized out of

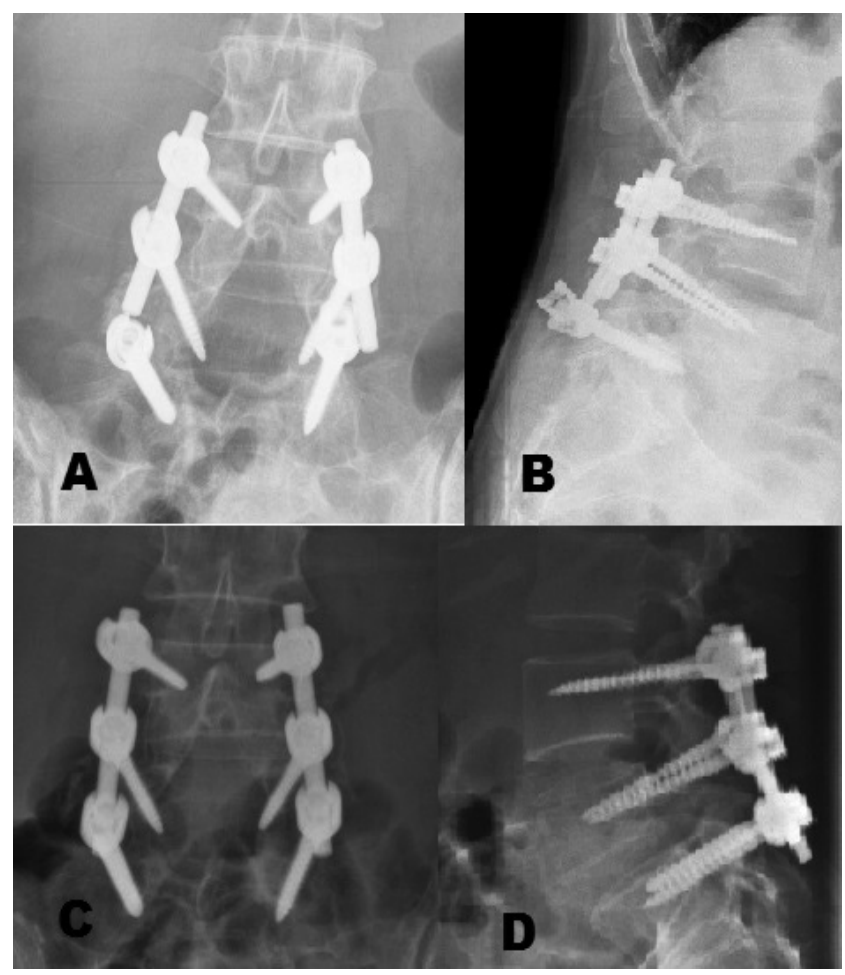

Figure 1. A and B; bilateral rod pull out owing to non-fusion after lifted a load of $25 \mathrm{~kg}$ (anteroposterior X-ray and lateral $\mathrm{X}$-ray), C and D; anteroposterior and lateral X-ray after revison surgery 
bed with brace on the $1^{\text {st }}$ postoperative day. The drain was pulled out on the $4^{\text {th }}$ postoperative day and the patients discharged on $4^{\text {th }}$ or $5^{\text {th }}$ postoperative day on condition that they use brace for 3 months.

\section{The Evaluation Fusion and Pain}

The patients were evaluated radiologically by lumbosacral X-ray and lumbar CT. On lumbosacral $X$-ray, fusion was evaluated as the formation of a solid bone bridge in the region including one upper and one lower segment of the spinal segment with spondylolisthesis and the transverse processes. On postoperative lumbar $\mathrm{CT}$, fusion evaluated as the development of a solid bone bridge in the region including the transverse and superior articular processes in the spinal segment with spondylolisthesis (Figure 2A, 2B), (Figure 3A, 3B). The patients were evaluated for fusion by $\mathrm{X}$-ray in the first one year and by 3D CT in later years. The patients were evaluated with the VAS and ODI pain scores in the preoperative and postoperative controls.

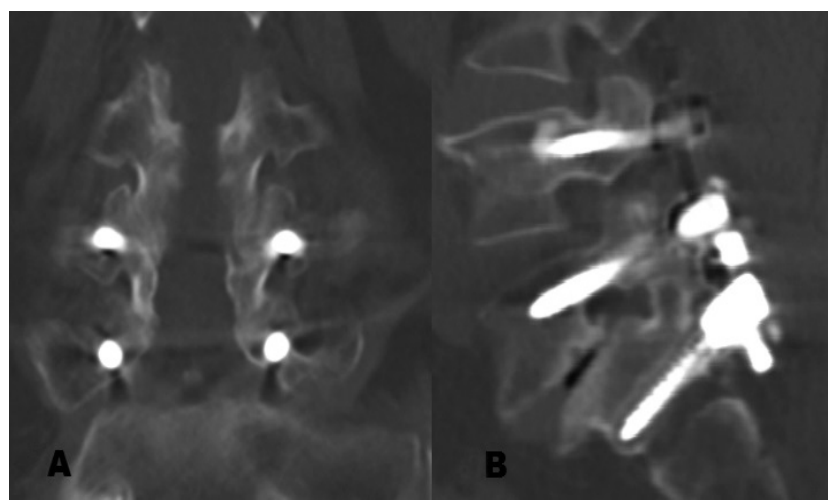

Figure 2. The expected fusion at coranal (A) and sagittal (B) 3D lumbar computed tomography view after 22 months later surgery

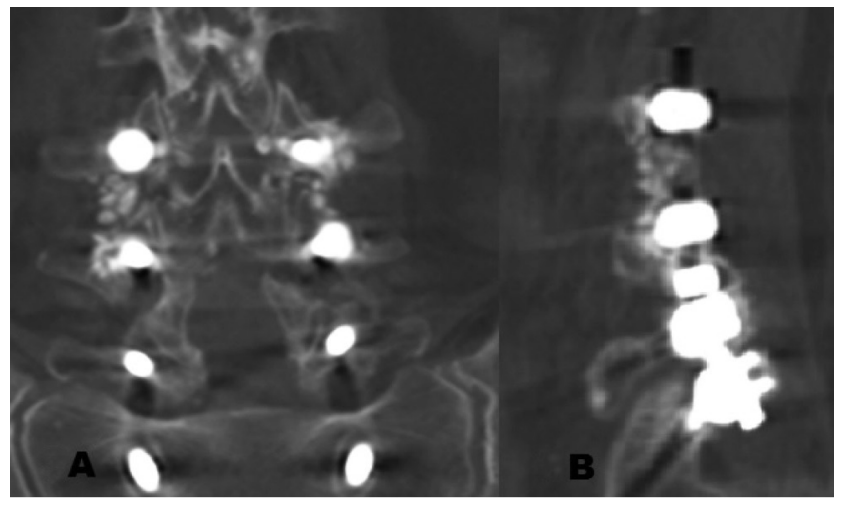

Figure 3. The unexpected fusion (pseudoarthrosis) at coranal (A) and sagittal (B) 3D lumbar computed tomography view after 12 months later surgery

\section{Statistical Analysis}

The Kolmogorov-Smirnov test was used to test whether the data were normally distributed. According to Kolmogorov-Smirnov test, preop ODI, postop ODI, preop VAS and postop VAS were nonnormally distributed but age and follow up time were normally distributed. We used nonparametric test for non-normally distributed variables and median $\left(25^{\text {th }}-75^{\text {th }}\right.$ percentiles) were given for descriptive statistics. For normally distributed variables mean \pm standard deviation were given. To evaluation of effect of posterolateral fixation on preop ODI, postop ODI, preop VAS and postop VAS we used the Wilcoxon test and to evaluation of effect of fusion on preop ODI, postop ODI, preop VAS and postop VAS. We used Mann-Whitney $U$ test for effects of patients' preop BMI which was $<30$ or $\geq 30$ on preop ODI and preop VAS scores. For fusion and chronic disease variables, descriptive statistics were given as frequency and percent. Chi-square test was used to determine whether there was a relation between fusion and chronic disease. $\mathrm{P}<0.05$ was accepted significiantly.

\section{Results}

When the pain scores of the patients who underwent segmental instrumentation were compared in the preoperative and postoperative periods, there was the significant decrease in pain scores in the patients with posterior fixation (the ODI and VAS scores in the preoperative and postoperative periods), respectively, 84 (73-90), 18 (12-24) and 8 (8-9), 2 (1-3) ( $p<0.001)$ (Table 1). While fusion occurred in $66 \%$ of the patients (Table 2 ), it did not occur in $34 \%$ of the patients (Table 3). The ODI and VAS scores of the patients with fusion and non-fusion were compared in the preoperative and postoperative periods [the ODI and VAS scores in the patients with fusion $(n=33)]$, respectively, 84 (78-89), 16 (12-24) and 9 (8-10), 2 (1-3) $(p<0.001)$, the $\mathrm{ODI}$ and VAS scores in the patients with non-fusion $(n=17)$, respectively, $74(65-91), 22(16-34)$ and 8 (8-9), 1 (1-4) $(p<0.001)$, (Table 3). Screw loosening occurred most frequently at the S1 level. Moreover, when the impact of chronic disease was evaluated on the formation of fusion, fusion occurred in 17 (51.5\%) of 29 patients with chronic disease but in 16 (48.5\%) of 21 patients without chronic disease. This results showed that the presence of chronic disease had no negative effect on the formation of fusion $(p=0.321)$ 
(Table 4). When the average BMI was considered as 30 and the preoperative and postoperative pain scores were compared between the patients with a $\mathrm{BMI}<30$ or $\geq 30$ body, there was no a statistically significant difference between the two groups in terms of patient satisfaction. The average operation time was 3.5 hours, the average amount of blood used was $550 \mathrm{cc}$ and the average length of stay in hospital was 5 days. There were no permanent motor and sensory deficits in patients after the surgery.

Table 1. Comprasion of preoperative and postoperative value of Oswestry Disability index and visual analogue score

\begin{tabular}{|l|l|l|l|}
\hline & Preop & Postop & $\mathbf{p}$ \\
\hline ODI & $84(73-90)$ & $18(12-24)$ & $<0.001$ \\
\hline VAS & $8(8-9.25)$ & $2(1-3)$ & $<0.001$ \\
\hline \multicolumn{2}{|l|}{ ODI: Oswestry Disability index, VAS: Visual analogue score } \\
\hline
\end{tabular}

Table 2. Comprasion of preopoperative and postoperative value of Oswestry Disability index and visual analogue score in patient who developed fusion

\begin{tabular}{|l|l|l|l|}
\hline & Preop & Postop & $\mathbf{p}$ \\
\hline ODI & $84(78-89)$ & $16(12-24)$ & $<0.001$ \\
\hline VAS & $9(8-10)$ & $2(1-3)$ & $<0.001$ \\
\hline
\end{tabular}

ODI: Oswestry Disability index, VAS: Visual analogue score

Table 3. Comprasion of preoperative and postoperative value of Oswestry Disability index and visual analogue score in patient who developed non-fusion

\begin{tabular}{|l|l|l|l|}
\hline & Preop & Postop & p \\
\hline ODI & $74(65-91)$ & $22(16-34)$ & $<0.001$ \\
\hline VAS & $8(8-9)$ & $1(1-4)$ & $<0.001$ \\
\hline
\end{tabular}

ODI: Oswestry Disability index, VAS: Visual analogue score

\begin{tabular}{|l|c|c|l|}
\hline \multicolumn{3}{|c|}{$\begin{array}{l}\text { Table 4. Comprasion of fusion rate in patient who have } \\
\text { chronic diseases or not }\end{array}$} & \multirow{2}{*}{ P } \\
\cline { 1 - 3 } \multirow{2}{*}{ Chronic disease } & \multicolumn{2}{|c|}{ Fusion } & \\
\cline { 2 - 3 } & Yes & No & \multirow{2}{*}{0.321} \\
\hline Yes & $17(51.5 \%)$ & $12(70.6 \%)$ & \\
\hline No & $16(48.5 \%)$ & $5(29.4 \%)$ & \\
\hline
\end{tabular}

\section{Discussion}

When looking at the results of our study, posterolateral fixation and fusion which is one of the surgical treatments of spondylolisthesis was observed to be an effective treatment in the medium and short term period in female patients in terms of patient satisfaction.

In the literature, many different surgical procedures have been described in terms of surgical treatment of spondylolisthesis (10-13). The main purpose of these surgical procedures is to eliminate pain caused by instability, to remove compression causing neurological deficits in patients, to restorate normal spinal alignment by correcting the sagittal imbalance secondary to spondylolisthesis and to prevent the progression of spondylolisthesis by advancing the areas of fusion in medium and long term. The PLF is presented as a gold standard method in spondylolisthesis by some authors because pedicle screw fixation systems have advantages such as theoretically the reduction of spondylolisthesis and the correction of deformity and also have been reported to increase fusion rates of rigid fixation (7,14-16). However, the extra cost of treatment, a wide surgical area, the presence of neurological or vascular complications related to the pedicle screw, an increase in the degeneration of the adjacent level, and the speculations about the increased pseudarthrosis rate with the rigid fixation are reported as the disadvantages of this method (7). In analysis of the studies of the literature, when fusion was added to posterolateral fixation, fusion rate was seen in approximately $81 \%-100 \%$ and rate of clinical success was seen in $60 \%-98 \%$ (17). In our study, fusion rate has remained at $66 \%$ level. There can be many reasons for this. When our patient group is analyzed, the patient group with a low fusion rate often consisted of elderly patients with a multi-level spondylolisthesis. We think that the reason for low fusion rate in this patient group was the loosening of pedicle screws and the deterioration of the initial state of rigid fixation due to osteoporosis in these patients. The deterioration of rigid fixation can cause micro-instability in the spine. In this condition, fusion rate may fall further in patients with osteoporosis. Therefore anterior column-assisted surgical treatment options may be preferable to provide an increase in the rate of fusion 
and to gain sufficient time for fusion in this patient group. The other possible factor is that the study group included the patients in the early postoperative period ( 1 year and not more). Moreover, another possible factor is that the differences in lifestyles, diet and genetic factors of the patients may have an effect on fusion.

The reason of lower back pain which is the most common complaint in patients with spondylolisthesis is instability associated with axial loading or rotation movement at the level of spondylolisthesis. When looking at the studies related to posterior fixation and fusion in the literature, a significant improvement was seen in VAS and ODI scores of patients in the early and medium term (18-20). In our study, when the ODI and VAS scores of the patients with fusion and non-fusion were compared in the preoperative and postoperative periods, the ODI and VAS scores were statistically significantly lower in the postoperative period than the preoperative period. Although the similar results in the patients with fusion and non-fusion seem like a paradox, in a study performed by Tsutsumimoto et al. (21) in a literature, when looking at short and medium term results of patients with fusion and nonfusion after PLF, there was no statistically significant difference between them. In the same study, they reported that age, comorbid conditions, fusion levels, gender, preoperative Japon Orthopedic Association score score and preoperative degree of slipping did not affect medium and short term clinical outcomes. A similar study was performed by Fischgrund (16), they reported $83 \%$ good results in patients who underwent instrumentation fusion and developed pseudarthrosis. These studies show that fusion status does not affect the clinical outcome of patients in the short and medium term in patients who underwent PLF without instrumentation. However, when clinical results of patients who underwent posterior fixation and fusion were compared with clinical results of patients who underwent laminectomy (without instrumentation) and fusion, the results were reported to be better in group with posterior fixation and fusion than group with laminectomy (without instrumentation) and fusion. In the same study, the poor clinical results of patients were shown to be an indicator of the progression of the degree of slip $(17,22)$. These studies suggest that rigid fixation and fusion increase patient satisfaction. However, it was reported that pseudarthrosis may develop in $5-25 \%$ of patients who underwent PLF and $50 \%$ of patients with pseudarthrosis may be asymptomatic (23). Moreover, it was reported that short-term results of dynamic systems which have been started to be used in degenerative spondylolisthesis in recent times were successful and similar to the results of fixation and PLF $(24,25)$. We think that short-term results of studies related to dynamic system may explain that patients develop pseudarthrosis but are asymptomatic patients. This is because dynamic fixation systems allow partial movement in the sagittal plane although they do not create instability as in the preoperative period. This situation occurs especially in patients who develop pseudoarthrosis around screw. This is because pseudarthrosis around screw may lead to a partial disruption of rigid structure of posterolateral fixation and so it may allow partial movement by acting as dynamic systems.

In the literature, it was reported that the success rates of fusion decreased and the risk of pseudoarthrosis increased in chronic diseases such as smoking, osteopenic bone structure, thyroid and growth hormone deficiency, chronic renal failure $(26,27)$. When our case series are analyzed, it is observed that chronic disease did not affect the formation of spinal fusion. In fact, this may seem like a reverse situation with literature. However, when our case series are analyzed, the patients with low fusion rate had end-stage renal failure and osteoporosis. Fusion rate is observed to be increased in patients who were diagnosed with hypothyroidism and then treated with hormone replacement. Similarly, in our case series, although there is no any problem in the formation of fusion in diabetic patients with proper glycemic control, when a secondary chronic disease such as osteoporosis is added to chronic diseases in these patients, the success fusion rate is seen to be decreased. This situation suggests that fusion rate may be close to normal in patients with hormone replacement therapy. In our case series, fusion success rate is seen to be decreased in age-related osteoporosis in female patients.

Another result of our study is that there was no statistically difference between BMIs groups of the patients and preoperative and postoperative complaints of the patients. In the literature, a study performed by Rhin et al. (28), the average BMI was considered as 30 and also the preoperative and 
postoperative results were compared between the patients with a $\mathrm{BMI}<30$ and $\geq 30$ body in terms of patient satisfaction. In this study, it was reported that a decrease in the complaints after spinal fusion in obese patients was similar to that in non-obese patients.

\section{Conclusion}

Consequently, it was demonstrated in this study that posterolateral fixation and fusion are an efficient treatment method in the medium and short term in female patients with spondylolisthesis in terms of patient satisfaction. Although fusion rates in female patients were similar to that in the literature, when a secondary chronic disease such as osteoporosis associated with aging was added to impair bone quality, fusion success rate was seen to be decreased in female patients with chronic diseases such as diabetes mellitus and hypothyroidism. Therefore, the different treatment strategies have been revealed to be required in patients with osteoporosis.

\section{Ethics}

Ethics Committee Approval: Retrospective study. Informed Consent: Informed consent was obtained from the patients.

Peer-review: External and internal peer-reviewed.

\section{Authorship Contributions}

Surgical and Medical Practices: Z.K., Concept: Z.K., A.T., Design: Z.K., O.B., Data Collection or Processing: Z.K., Y.S.A., O.B., Analysis or Interpretation: H.Ö., Literature Search: Z.K., A.T., Writing: Z.K.

Conflict of Interest: No conflict of interest was declared by the authors.

Financial Disclosure: The authors declared that this study received no financial support.

\section{References}

1. Liu XY, Wang YP, Qiu GX, Weng XS, Yu B. Meta analysis of circumferential fusion versus PLFin lumbarspondylolisthesis. J Spinal Disord Tech 2014; 27: 282-93.

2. Wiltse LL, Newman PH, Macnab I. Classification of spondylolisis and spondylolisthesis. Clin Orthop Relat Res 1976; 117: 23-9.

3. Meyerding HW. Spondylolisthesis. Surg Gynecol Obstet 1932; 54: 371-80.

4. Bridwell KH. Surgical treatment of high-grade spondylolisthesis. Neurosurg Clin N Am 2006; 17: 331-8.
5. Rowe GG, Roche MB. The etiology of seprate neural arch. J Bone Joint Surg Am 1953; 35: 102-10.

6. Syrmou E, Tsitsopoulos PP, Marinopoulos D, Tsonidis C, Anagnostopoulos I, Tsitsopoulos PD. Spondylolysis: a review and reappraisal. Hippokratia 2010; 14: 17-21.

7. Jacobs WC, Vreeling A, De Kleuver M.Fusion for low- grade adult isthmic spondylolisthesis: a systematic review of the literature. Eur Spine J 2006; 15: 391-402.

8. Labelle H, Mac-Thiong JM, Roussouly P. Spino-pelvic sagittal balance of Spondylolisthesis: a review and classification. Eur Spine J 2011; 5: 641-6.

9. Wang SJ, Han YC, Liu XM, Ma B, Zhao WD, Wu DS, et al. fusion techniques for adult isthmic spondylolisthesis: a systematic review. Arch Orthop Trauma Surg 2014; 134: 777-84.

10. Aunoble $S$, Hoste $D$, Donkersloot $P$, Liquois $F$, Basso $Y$, Le-Huec JC. Video-assisted ALIF with cage and anterior plate fixation for L5-S1 spondylolisthesis. J Spinal Disord Tech 2006; 19: 471-6.

11. Kim DH, Jeong ST, Lee SS. Posterior lumbar interbody fusion using a unilateral single cage and a local morselized bone graft in the degenerative lumbar spine. Clin Orthop Surg 2009; 1: 214-21.

12. Lee DY, Lee SH, Maeng DH. Two-level anterior lumbar interbody fusion with percutaneous pedicle screw fixation: a minimum 3-year follow-up study. Neurol Med Chir (Tokyo) 2010; 50: 645-50.

13. Hioki A, Miyamoto K, Hosoe H, Sugiyama S, Suzuki N, Shimizu K. Cantilever transforaminal lumbar interbody fusion for upper lumbar degenerative diseases (minimum 2 years follow up). Yonsei Med J 2011; 52: 314-21.

14. Boden SD. Overview of the biology of lumbar spine fusion and principles for selecting a bone graft substitute. Spine 2002; 27: 26-31.

15. Carreon LY, Djurasovic M, Glassman SD, Sailer P. Diagnostic accuracy and reliability of fine-cut CT scans with reconstructions to determine the status of an instrumented posterolateral fusion with surgical exploration as reference standard. Spine 2007; 32: 892-5.

16. Fischgrund JS. The argument for instrumented decompressive posterolateral fusion for patients with degenerative spondylolisthesis and spinal stenosis. Spine 2004; 29: 173-4.

17. Herkowitz HN, Kurz LT. Degenerative lumbar spondylolisthesis with spinal stenosis. A prospective study comparing decompression with decompression and intertransverse process arthrodesis. J Bone Joint Surg Am 1991; 73: 802-8.

18. Müslüman AM, Yılmaz A, Cansever T, Cavuşoğlu H, Colak I, Genç HA, et al. Posterior lumbar interbody fusion versus posterolateral fusion with instrumentation in the treatment of low-grade isthmic spondylolisthesis: midterm clinical outcomes. J Neurosurg Spine 2011; 14: 488-96.

19. Ekman P, Möller H, Tullberg T, Neumann P, Hedlund R. Posterior lumbar interbody fusion versus posterolateral fusion in adult isthmic spondylolisthesis. Spine (Phila Pa 1976) 2007; 32: 2178-83.

20. Nayak MT, Sannegowda RB. Clinin and radiological outcome in cases of posterolateral fusion with insturmntation for lumbar spondylolisthesis. J Clin Diagn Res 2015; 9: 17-21. 
21. Tsutsumimoto $T$, Shimogata $M$, Yoshimura $Y$, Misawa $H$. Union versus nonunion after posterolateral lumbar fusion: a comparison of long-term surgical outcomes in patients with degenerative lumbar spondylolisthesis. Eur Spine J 2008; 17: 1107-12.

22. Bridwell KH, Sedgewick TA, O'Brien MF, Lenke LG, Baldus C. The role of fusion and instrumentation in the treatment of degenerative spondylolisthesis with spinal stenosis. J Spinal Disord 1993; 6: 461-72.

23. Rager O, Schaller K, Payer M, Tchernin D, Ratip O, Tessitore E. SPECT/CT in differentiation of pseudarthrosis from other causes of back pain in lumbar spinal fusion: report on consecutive cases. Clin Nucl Med 2012; 37: 339-43.

24. Ohtonari T, Nishihara N, Suwa K, Ota T, Koyama T. Dynamic stabilization for degenerative spondylolisthesis and lumbar spinal instability. Neurol Med Chir (Tokyo) 2014; 54: 698-706.
25. Schnake KJ, Schaeren S, Jeanneret B. Dynamic stabilization in addition to decompression for lumbar spinal stenosis with degenerative spondylolisthesis. Spine (Phila Pa 1976). 2006; 31: 442-9.

26. Larsen JM, Capen DA. Pseudoarthrosis of the lumbar spine. J Am Acad Orthop Surg 1997; 5: 153-62.

27. Kanaya K, Kato Y, Murata Y, Wada H, Wada K, Shimamoto S, et al. Low parathyroid hormone levels in patients who underwent/ would undergo hemodialysis result in bone graft failure after posterolateral fusion. Spine (Phila Pa 1976) 2014; 39: 327-31.

28. Rhin JA, Radcliff K, Hilibrand AS, Anderson DT, Zhao W, Luire $J$, et al. Does obesity affect outcomes of treatment for lumbar stenosis and degenerative spondylolisthesis? Anaylsis of the spine patient outcomes research trial (SPORT). Spine (Phila Pa 1976). 2012; 37: 1933-46. 